\title{
A Survey of Innovative Reimbursement Models in Spine Care
}

\section{Citation}

Kazberouk, Alexander D. 2018. A Survey of Innovative Reimbursement Models in Spine Care. Doctoral dissertation, Harvard Medical School.

\section{Permanent link}

http://nrs.harvard.edu/urn-3:HUL.InstRepos:41973499

\section{Terms of Use}

This article was downloaded from Harvard University's DASH repository, and is made available under the terms and conditions applicable to Other Posted Material, as set forth at http:// nrs.harvard.edu/urn-3:HUL.InstRepos:dash.current.terms-of-use\#LAA

\section{Share Your Story}

The Harvard community has made this article openly available.

Please share how this access benefits you. Submit a story.

\section{Accessibility}


Scholarly Report submitted in partial fulfillment of the MD Degree at Harvard Medical School

Date: 10 December 2017

Student Name: Alexander Kazberouk, BS

Scholarly Report Title: Improving Value in Spine Care by Understanding Cost Variation and Innovative Reimbursement Models in Spine Surgery

Mentor Name(s) and Affiliations: Kevin McGuire, MD, MS, Spine Center, DartmouthHitchcock Medical Center (previously Department of Orthopaedics, Beth Israel Deaconess Medical Center)

\section{Collaborators, with Affiliations:}

Bruce Landon, MD, MBA, Division of General Medicine and Primary Care, Beth Israel Deaconess Medical Center

Iftach Sagy, MD, Department of Clinical Research Center, Soroka University Medical Center, and Faculty of Health Sciences Ben-Gurion University of the Negev, Beer-Sheva, Israel. I

Victor Novack, MD, PhD, Department of Clinical Research Center, Soroka University Medical Center, and Faculty of Health Sciences Ben-Gurion University of the Negev, Beer-Sheva, Israel. 


\section{Abstract 1}

TITLE: A Survey of Innovative Reimbursement Models in Spine Care.

Kazberouk A, McGuire K, Landon BE.

Purpose: The United States spends $\$ 90$ billion annually on medical expenses for low back pain. One approach to promoting high-quality, cost-effective care is through bundled payments and other reimbursement models wherein physicians are held accountable for costs and utilization. The aim of the study was to describe innovative reimbursement models in spine care and gather perspectives on the future of spine care reimbursement

Methods: Through literature review and discussions with leaders in the field, we identified organizations that were engaged in bundled payment initiatives for spine care and surgery. These included healthcare systems, physician groups, organizations helping to set up bundles, and a large employer. We conducted interviews to understand the background and specific features of each initiative, generalizable success factors and challenges, and perspectives on the future of spine reimbursement.

Results: We interviewed 24 stakeholders across 18 organizations that collectively perform approximately 12,000 inpatient spine surgeries annually. Fee-for-service reimbursement accounts for a majority of revenue, but several organizations expect $30 \%$ to $45 \%$ of their spine volume to be covered under bundled payments within 3 years and cite new patient volume, increased surgical yield, and financial benefits from efficiency improvements as reasons for adopting bundled payments. Current initiatives are heterogeneous, but share similar success factors and challenges. Institutions are more hesitant to adopt risk-based payment models for chronic back care, citing difficulty modeling risk, patient heterogeneity, and difficulty aligning incentives.

Conclusions: Payment models outside of the traditional fee-for-service paradigm are emerging in spine care. Providers that preemptively adopt bundled payments can increase patient volumes from payers seeking cost-effective care. Going forward, organizations should begin considering reimbursement models that focus on noninterventional spine care. Finally, developments in spine reimbursement may apply to other procedure-based specialties, including orthopedics and cardiology. 


\section{Abstract 2}

TITLE: Understanding the Extent and Drivers of Interphysician Cost Variation for Spine Procedures.

Kazberouk A, Sagy I, Novack V, McGuire K.

Purpose: Spine care accounts for $\$ 90$ billion in health care expenditures in the United States. Past findings demonstrate regional variation in surgery rates and high intersurgeon variation for anterior cervical discectomies/fusions. However, less has been done to examine intersurgeon variation in resource use across multiple procedures while adjusting for patient characteristics outside of a surgeon's control. This study aimed to quantify intersurgeon variation for hospital costs of four spine procedures while adjusting for patient comorbidities and demographic factors.

Methods: We examined intersurgeon variation for 1241 elective spine procedures at one facility for 3 years. The procedures included 1 to 2 level cases of anterior cervical discectomies/fusions, posterior lumbar decompressions/fusions, posterior laminectomies, and lumbar discectomies. We isolated mean and median costs by surgeon and adjusted for patient demographics, comorbidities, and procedure types. Finally, we examined variation in subcategories such as instrumentation and inpatient stay costs to determine which contribute to total cost variation.

Results: Unadjusted costs per surgeon varied by a factor of 1.32 to 1.81 between lowest and highest cost surgeon depending on procedure. After adjusting for patient features and procedure, variation was reduced to 1.31x. Of the seven surgeons who had sufficient patient volume, one was significantly less costly $(-\$ 1,462$ per procedure) whereas three were significantly more costly than mean $(+\$ 685,+\$ 839,+\$ 702$ per procedure). Intersurgeon differences in supply and operating room costs largely accounted for total variation, though actual drivers of variation were surgeon-specific.

Conclusions: Surgeons vary in average cost for spine procedures, though variation is more modest once adjusted for patient characteristics. Data on procedure-level variation should be discussed with individual surgeons to shift practice patterns. Finally, the comparison methodology can be applied to other procedures and specialties. 


\section{Contribution to Work}

My project involved two distinct components both looking broadly at the theme of cost and reimbursement in spine care.

The first component was a qualitative survey of new reimbursement models in spine care. For this project, I worked with Dr. Landon to develop the research questions based on our interest in reimbursement innovation. I reviewed existing scientific literature and news articles on the subject developed an interview guide with feedback from Dr. Landon and Dr. McGuire. I also went through the process of getting IRB approval for this work. Next, I relied on a mentor contacts, my own network, and news/journal articles to identify potential interviewees. I was responsible for coordinating and leading the interviews, taking notes, and thematically summarizing the conversations. Dr. Landon and Dr. McGuire participated in some of the interviews and asked follow-up questions. Following each interview, I sent my notes to the interviewees to confirm accuracy. I wrote the first draft of the manuscript and then revised it based on feedback from Dr. Landon and Dr. McGuire. Finally, I submitted the manuscript for review and worked with my coauthors to revise and resubmit the article prior to acceptance.

My second component examined cost variation among spine surgeries at BIDMC. Prior to launching any new reimbursement models, it was important to understand existing costs and cost variation. Therefore, we examined costs for surgeries by procedure type, by surgeon, and by cost component (e.g., pharmacy, radiology, supplies, etc). I drew upon my consulting experience to design some of the analyses but also relied on input from Dr. McGuire to think about modeling and more generalizable findings. The cost data was available, so my role was cleaning up the data and running analyses which did not require extensive statistical modeling to generate Table 1 (patient characteristics), Table 2 (unadjusted costs by procedure by surgeon), and Table 4 (subcategory costs and total costs by procedure). Separately, Dr. Novack and Dr. Sagy built a model for risk adjustment to account for patient demographics, comorbidities, and procedure types (Table 3 ) and another one to explain how much of overall variation was due to each component cost variation (Table 5). Next, I wrote the manuscript draft with input for the methodology section from Dr. Novack and Dr. Sagy and modified the draft based on feedback from Dr. McGuire. Finally, I was responsible for submitting and revising the manuscript.

My final goal was to work on a business plan for the BIDMC spine surgery center. However, due to changing priorities and time constraints, I ultimately ended up prioritizing the two components above.

Kazberouk, Alex, Kevin McGuire, and Bruce E. Landon. "A survey of innovative reimbursement models in spine care." Spine 41.4 (2016): 344-352.

https://www.ncbi.nlm.nih.gov/pubmed/26555826

Kazberouk, Alex, et al. "Understanding the extent and drivers of interphysician cost variation for spine procedures." Spine 41.13 (2016): 1111-1117

https://www.ncbi.nlm.nih.gov/pubmed/26780612 